\title{
Rhabdomyolysis-induced acute kidney injury in a patient with non-compliance to levothyroxine therapy
}

\author{
Ayesha Ghayur1', Qurrat Elahi², Chinmay Patel³ and Rishi Raj ${ }^{2} 4$ \\ 'Department of Medicine, McMaster University, Hamilton, Ontario, Canada, 2Department of Family Medicine, \\ Pikeville Medicine Center, Pikeville, Kentucky, USA, ${ }^{3}$ Department of Nephrology, Southern Kidney Associates, \\ Shreveport, LA, USA, and "Division of Endocrinology, Diabetes and Metabolism, Department of Internal Medicine, \\ Pikeville Medical Center, Pikeville, Kentucky, USA
}

\author{
Correspondence \\ should be addressed \\ to R Raj \\ E-mail \\ rishiraj91215@gmail.com
}

\section{Summary}

Hypothyroidism is a common medical condition and is often easily managed with excellent outcomes, when treated adequately. Compliance with levothyroxine (LT4) therapy is often compromised because of the need for a daily and lasting schedule. Overt rhabdomyolysis due to under-treatment or non-compliance is a rare occurrence. We report a case of rhabdomyolysis leading to acute kidney injury (AKI) on chronic kidney disease (CKD) requiring hemodialysis (HD) in a 68-year-old Caucasian male due to non-compliance with levothyroxine (LT4) therapy. Our patient 'ran out of levothyroxine' for approximately 4 weeks and developed gradually progressive muscle pain. The diagnosis of severe AKI due to rhabdomyolysis was made based on oliguria, elevated creatinine kinase (CK), and renal failure. Resuming the home dose of LT4 failed to correct CK levels, and there was a progressive decline in renal function. Although increasing doses of LT4 and three cycles of HD improved CK levels, they remained above baseline at the time of discharge. The patient recovered gradually and required HD for 4 weeks. CK levels normalized at 6 weeks. Through this case report, we highlight that non-compliance with LT4 therapy can lead to life-threatening complications such as renal failure and hence the need to educate patients on the significance of compliance with LT4 therapy should be addressed.

\section{Learning points}

- Non-compliance to levothyroxine therapy is common and can lead to serious complications, including rhabdomyolysis.

- Rhabdomyolysis is an uncommon presentation of hypothyroidism and severe rhabdomyolysis can result in renal failure requiring hemodialysis.

- Rhabdomyolysis associated with hypothyroidism can be further exacerbated by concomitant use of statins.

\section{Background}

Hypothyroidism is frequently associated with myalgias, muscle stiffness, easy fatigability, and occasionally some degree of myopathy with mildly elevated muscle enzymes. Rarely, hypothyroidism may be complicated by rhabdomyolysis, the rapid destruction of skeletal muscle with the release of myoglobin, creatine kinase, urate, and electrolytes into the circulation (1).

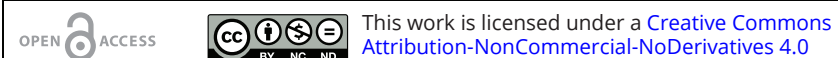
International License.
}

Although overt rhabdomyolysis in patients with hypothyroidism is a known complication, severe rhabdomyolysis leading to acute kidney injury (AKI) requiring hemodialysis (HD) is extremely rare. Factors that contribute to rhabdomyolysis in hypothyroidism include strenuous physical activity, medication non-compliance, and concomitant use of medications causing myopathy, (c) 2021 The authors
https://edm.bioscientifica.com/
Published by Bioscientifica Ltd 
for example, statin and fibrates. Cases of rhabdomyolysis are reported in patients with undiagnosed hypothyroidism who take statins even without any precipitating factor; however, extreme creatinine kinase (CK) elevation is extremely rare (1). Severe rhabdomyolysis and AKI can be potentially life-threatening due to the resultant metabolic derangements seen in these patients.

Medication non-adherence, in general, is a prevalent issue. The reported prevalence of medication noncompliance ranges from 25 to 50\% (2). Contributing factors such as disease symptoms, patient demographics, insurance coverage, and psychosocial factors play a vital role. Levothyroxine (LT4) has poor absorption and needs to be taken on an empty stomach, which further exacerbates compliance. Once-weekly regimens have also been suggested and have been successfully used to achieve normal thyroid-stimulating hormone levels (TSH) in some patients (3). Nonetheless, non-compliance to LT4 therapy remains a frequently encountered problem in clinical practice. Here, we describe a case of rhabdomyolysisinduced severe AKI in chronic kidney disease (CKD) secondary to non-compliance to LT4 therapy.

\section{Case presentation}

A 68-year-old Caucasian male presented to the emergency room with a 2-week history of worsening fatigue and generalized weakness, accompanied by decreased urine output and bilateral lower extremities pain. Systematic physical was unremarkable except for nausea and reduced appetite. There was no history of recent physical exertion, prolonged immobilization, crush injury, electrical injury, traumatic injury, heat exposure, or seizures. The patient denied any use of alcohol or illicit drugs. A review of prior lab work-up (done 3 months ago) did not reveal hypokalemia, hypophosphatemia, or other electrolyte abnormalities. Past medical history was significant for coronary artery disease, heart failure with reduced ejection

fraction, hypertension, dyslipidemia, primary hypothyroidism, type 2 diabetes mellitus, and chronic kidney disease stage 3A (attributed to underlying suspected diabetic and hypertensive nephropathy).

Home medications included aspirin $81 \mathrm{mg}$ daily, levothyroxine $200 \mu \mathrm{g}$ daily, metoprolol $25 \mathrm{mg}$ daily, doxazosin $2 \mathrm{mg}$ daily, amlodipine $5 \mathrm{mg}$ daily, fosinopril $40 \mathrm{mg}$ twice daily, metformin $500 \mathrm{mg}$ twice daily, and rosuvastatin $40 \mathrm{mg}$ daily. For LT4, the patient reported that 'he ran out of it' for a period of approximately 4 weeks and resumed it a few days before coming to the hospital (3-4 days). On presentation, he was hemodynamically stable with blood pressure $139 / 85 \mathrm{mmHg}$, temperature $97^{\circ} \mathrm{F}$, respiratory rate 18 per minute, pulse rate 80 b.p.m., and oxygen saturation of $99 \%$ on room air. His BMI was 38.37 $\mathrm{kg} / \mathrm{m}^{2}$. Musculoskeletal examination revealed proximal muscle weakness with power $3 / 5$ in bilateral lower extremities and mild tenderness of the thigh muscles. The remaining physical exam was unremarkable.

\section{Investigation}

Laboratory workup on admission showed elevated creatinine $13.1 \mathrm{mg} / \mathrm{dL}$, blood urea nitrogen (BUN) $101 \mathrm{mg} /$ $\mathrm{dL}$, low eGFR of $4.0 \mathrm{~mL} / \mathrm{min} / 1.73 \mathrm{~m}^{2}$, and elevated creatinine kinase (CK) $69500 \mathrm{U} / \mathrm{L}$. Baseline creatinine was $1.4 \mathrm{mg} / \mathrm{dL}$. Arterial blood gas (ABG) showed pH 7.256 and bicarbonate 13.4, suggestive of metabolic acidosis. Urine toxicology was negative. Work up for further evaluation of rhabdomyolysis revealed elevated TSH of $55.8 \mathrm{uIU} / \mathrm{mL}(0.45-4.5 \mathrm{uIU} /$ $\mathrm{mL})$ with free $\mathrm{T} 40.61 \mathrm{ng} / \mathrm{dL}(0.8-1.8 \mathrm{ng} / \mathrm{dL})$ suggestive of hypothyroidism. The rest of the laboratory studies are summarized in Table 1 and showed anemia, hyperkalemia, hyperphosphatemia, metabolic acidosis, transaminitis, and secondary hyperparathyroidism. A review of labs from previous workup (3 months ago) revealed normal thyroid function tests (TSH $1.6 \mathrm{uIU} / \mathrm{mL}$ and free $\mathrm{T} 41.3 \mu \mathrm{g} / \mathrm{dL}$ ) on LT4 $200 \mu \mathrm{g}$ and baseline CKD stage 3B (EGFR $51 \mathrm{~mL} / \mathrm{min} / 1.73 \mathrm{~m}^{2}$ with baseline creatinine $1.4 \mathrm{mg} / \mathrm{dL}$ ). Hence, the patient was diagnosed with severe rhabdomyolysis secondary to noncompliance with LT4 therapy in the presence of concurrent statin use, leading to AKI.

\section{Treatment}

Rosuvastatin, fosinopril, and metformin were stopped, and aggressive intravenous hydration was initiated. Sodium bicarbonate was used to address both metabolic acidosis and rhabdomyolysis. Sevelamer was used for hyperphosphatemia. The home dose of oral LT4 $200 \mu \mathrm{g}$ was reinitiated. Despite 2 days of aggressive treatment, the patient remained oliguric, CK remained elevated, and he started to have volume overload. Subsequently, on day 3, intermittent hemodialysis was initiated with a high flux Revaclear 300 filter. Because of persistently elevated CK levels, a decision was made to increase his LT4 dose to $250 \mu \mathrm{g}$ daily. The patient underwent three sessions of HD during the course of his hospitalization.

\section{Outcome and follow-up}

On day 6, CK was still elevated (41 $514 \mathrm{U} / \mathrm{L}$ ), and there were no signs of renal recovery and hence outpatient dialysis 
Table 1 Laboratory results on admission.

\begin{tabular}{|c|c|c|}
\hline Laboratory test & Level & Reference range \\
\hline WBCs & $8.4 \mathrm{k} / \mu \mathrm{L}$ & $3.7-10.3 \mathrm{k} / \mu \mathrm{L}$ \\
\hline $\mathrm{RBCs}$ & $3.270 \mathrm{M} / \mu \mathrm{L}$ & $3-5.2 \mathrm{M} / \mu \mathrm{L}$ \\
\hline Hemoglobin & $9.7 \mathrm{~g} / \mathrm{dL}$ & $11.2-15.7 \mathrm{~g} / \mathrm{dL}$ \\
\hline Hematocrit & $28.7 \%$ & $34-45 \%$ \\
\hline Platelets & $189 \mathrm{k} / \mu \mathrm{L}$ & $155-369 \mathrm{k} / \mu \mathrm{L}$ \\
\hline Glucose & 93 mg/dL & $74-90$ mg/dL \\
\hline Sodium & $133 \mathrm{mmol} / \mathrm{L}$ & $136-145 \mathrm{mmol} / \mathrm{L}$ \\
\hline Potassium & $5.5 \mathrm{mmol} / \mathrm{L}$ & $3.7-4.8 \mathrm{mmol} / \mathrm{L}$ \\
\hline Bicarbonate & $17 \mathrm{mmol} / \mathrm{L}$ & $22-29 \mathrm{mmol} / \mathrm{L}$ \\
\hline Chloride & $101 \mathrm{mmol} / \mathrm{L}$ & 97-107 mmol/L \\
\hline Calcium & $8.5 \mathrm{mg} / \mathrm{dL}$ & 8.9-10.2 mg/dL \\
\hline Magnesium & $2.8 \mathrm{mg} / \mathrm{dL}$ & $1.9-2.4 \mathrm{mg} / \mathrm{dL}$ \\
\hline Phosphorus & $7.6 \mathrm{mg} / \mathrm{dL}$ & $2.5-4.5 \mathrm{mg} / \mathrm{dL}$ \\
\hline Albumin & $3.5 \mathrm{~g} / \mathrm{dL}$ & $3.3-4.6 \mathrm{~g} / \mathrm{dL}$ \\
\hline Blood urea nitrogen & $101 \mathrm{mg} / \mathrm{dL}$ & $0-30 \mathrm{ng} / \mathrm{dL}$ \\
\hline Creatinine & $13.10 \mathrm{mg} / \mathrm{dL}$ & $0.60-1.10 \mathrm{mg} / \mathrm{dL}$ \\
\hline Estimated GFR & $4.0 \mathrm{~mL} / \mathrm{min} / 1.73 \mathrm{~m}^{2}$ & $>60 \mathrm{~mL} / \mathrm{min} / 1.73 \mathrm{~m}^{2}$ \\
\hline Aspartate transaminase & $1693 \mathrm{U} / \mathrm{L}$ & 9-36 U/L \\
\hline Alanine transaminase & 386 U/L & $8-33 \mathrm{U} / \mathrm{L}$ \\
\hline Alkaline phosphatase & $147 \mathrm{U} / \mathrm{L}$ & $46-142 \mathrm{U} / \mathrm{L}$ \\
\hline Total protein & $7.5 \mathrm{~g} / \mathrm{dL}$ & $6.3-7.9 \mathrm{~g} / \mathrm{dL}$ \\
\hline Parathyroid hormone & $342 \mathrm{pg} / \mathrm{mL}$ & $15-65 \mathrm{pg} / \mathrm{mL}$ \\
\hline Vitamin D total & $29.6 \mathrm{ng} / \mathrm{mL}$ & $30.0-100 \mathrm{ng} / \mathrm{mL}$ \\
\hline Thyroid stimulating hormone (TSH) & $55.800 \mathrm{ulU} / \mathrm{mL}$ & $0.358-3.740 \mathrm{ulU} / \mathrm{mL}$ \\
\hline Free thyroxine (FT4) & $0.61 \mathrm{ng} / \mathrm{dL}$ & $0.8-1.8 \mathrm{ng} / \mathrm{dL}$ \\
\hline Total thyroxine (TT4) & $4.0 \mu \mathrm{g} / \mathrm{dL}$ & $4.8-13.9 \mu \mathrm{g} / \mathrm{dL}$ \\
\hline Total T3 (TT3) & $27 \mathrm{ng} / \mathrm{dL}$ & $71-180 \mathrm{ng} / \mathrm{dL}$ \\
\hline Hepatitis panel & Negative & \\
\hline
\end{tabular}

was arranged. He was discharged home on aspirin $81 \mathrm{mg}$ daily, insulin glargine 5 units at bedtime, levothyroxine $250 \mu \mathrm{g}$ daily, metoprolol $25 \mathrm{mg}$ daily, doxazosin $2 \mathrm{mg}$ daily, and amlodipine $5 \mathrm{mg}$ daily. The patient needed HD for 4 weeks. At 6 weeks follow-up, his laboratory workup revealed CK $105 \mathrm{U} / \mathrm{L}$, TSH $6.6 \mathrm{uIU} / \mathrm{mL}$, free T4 $0.94 \mathrm{ng} / \mathrm{dL}$, creatinine $1.42 \mathrm{mg} / \mathrm{dL}$ and eGFR $54 \mathrm{~mL} / \mathrm{min} / 1.73 \mathrm{~m}^{2}$.

\section{Discussion}

Hypothyroidism is a common and well-known medical condition with a prevalence of 3.7\% (1999-2002) (4). It has a broad spectrum of clinical presentations including, but not limited to, fatigue, cold intolerance, bradycardia, constipation, menstrual irregularities, and dry skin. Rarely, hypothyroidism can lead to muscle damage, ranging from asymptomatic elevations of the CK level to significant rhabdomyolysis. Thyroid myopathy is a well-recognized but poorly understood complication of hypothyroidism. The pathophysiology of rhabdomyolysis is believed to be due to inhibition of mitochondrial oxidative phosphorylation resulting in decreased ATP production and dysregulation of multiple biochemical pathways. Studies have also suggested changes in muscle fibers from fast twitching to slow twitching, deposition of glycosaminoglycans, poor contractility of actin-myosin units, low myosin ATPase activity or low ATP turnover in the skeletal muscles (5). There is lack of any clear correlation between the severity of hypothyroidism and CK levels. Hence, hypothyroidism is a crucial differential when evaluating unexplained CK elevations.

Rhabdomyolysis is typically defined by elevated CK level, at least five times above the upper limit of normal, and is usually greater than 5000 international units/L. In our patient, $\mathrm{CK}$ was massively elevated to more than 350 times the upper limit of normal. We believe that concomitant use of statin in our patient might have resulted in a higher degree of myopathy (6). Additionally, the use of other nephrotoxic drugs in our patient, such as metformin and fosinopril, might have exacerbated the impact of rhabdomyolysis, leading to rapid deterioration of AKI to end-stage renal disease and overt acidosis.

Rhabdomyolysis leads to the release of a hemecontaining protein, myoglobulin, into circulation. Multiple mechanisms are responsible for myoglobininduced renal injury. It is toxic to renal tubules and causes renal vasoconstriction and the formation of tubular casts. However, myoglobin has poor sensitivity to the diagnosis of rhabdomyolysis. Elevated CK levels are considered the most sensitive marker. The frequency of AKI in patients with rhabdomyolysis ranges from 15 to $50 \%$ and is directly associated with the degree of CK elevation (7). AKI due to rhabdomyolysiscan beworsened by associated dehydration. Initial management of rhabdomyolysis consists of intravenous fluids administration and correction of any electrolyte abnormalities. Despite adequate intravenous hydration and discontinuation of statins, our patient continued to have deterioration in renal function and once thyroid function tests revealed hypothyroidism, thyroid hormone replacement was reinitiated. Unfortunately, our patient's renal function continued to deteriorate further, necessitating the initiation of HD.

Management of hypothyroidism requires life-long LT4 therapy. However, as with any other chronic condition, adherence to medical management is common. Current literature suggests that up to $50 \%$ of the patients may have poor compliance to medications, which is attributed to several underlying factors (8). Although patients in clinical trials tend to have better medication adherence, this can be significantly misleading as only an average adherence rate is reported among patients with chronic disease. Furthermore, a Cochrane database analysis assessed that interventions to enhance patient adherence 
to prescribed medications did not show any improvement (9). Persistently elevated TSH levels despite the patient's reported use of LT4 suggest poor adherence to LT4. In these cases, poor absorption must be differentiated from non-compliance by administering a weight-based weekly oral dose of LT4 and measurement of free T4 at baseline and $2 \mathrm{~h}$ (thyroxine absorption test). Adequate free T4 levels among patients with poor compliance rules out any malabsorption syndrome (10). In our case, the thyroxine absorption test was not done as the patient admitted to non-compliance. Occasionally, in some patients with poor compliance, a once-weekly dose of LT4 is administered (3).

In summary, in our patient, non-compliance with LT4 therapy was likely the principal etiology of rhabdomyolysis induced AKI. An extreme elevation in CK levels can be attributed to the concomitant use of statin. The insidious development of such CK levels and AKI highlight the overt presentation of rhabdomyolysis in hypothyroidism and the importance of medication compliance. Healthcare workers should be aware of this rare side effect of hypothyroidism. They must always explore non-compliance with LT4 therapy among patients on chronic LT4 replacement. Hence, our case highlights the importance of screening for medication noncompliance in patients with hypothyroidism presenting with rhabdomyolysis and AKI.

\section{Declaration of interest}

The authors declare that there is no conflict of interest that could be perceived as prejudicing the impartiality of the research reported.

\section{Funding}

Funding for this case report was provided by the Education Department of Pikeville Medical Center, Pikeville, KY, USA.

\section{Patient consent}

Written informed consent was obtained from the patient for the publication of the submitted article.

\section{Author contribution statement}

CP was the patient's nephrologist and was directly involved in the patient's care. AG and QE were part of the treatment team, performed literature overview, and wrote the manuscript. RR was the supervising provider and was directly involved in writing the manuscript and literature review. All providers had direct permission of $\mathrm{CP}$, the primary physician responsible for the patient.

\section{References}

1 Yeter E, Keles T, Durmaz T \& Bozkurt E. Rhabdomyolysis due to the additive effect of statin therapy and hypothyroidism: a case report. Journal of Medical Case Reports 20071 1-2. (https://doi. org/10.1186/1752-1947-1-130)

2 Haynes RB, Montague P, Oliver T, McKibbon KA, Brouwers MC \& Kanani R. Interventions for helping patients to follow prescriptions for medications. Cochrane Database of Systematic Reviews 20002 CD000011. (https://doi.org/10.1002/14651858.CD000011)

3 Grebe SK, Cooke RR, Ford HC, Fagerstrom JN, Cordwell DP, Lever NA, Purdie GL \& Feek CM. Treatment of hypothyroidism with once weekly thyroxine. Journal of Clinical Endocrinology and Metabolism 199782 870-875. (https://doi.org/10.1210/jcem.82.3.3830)

4 Aoki Y, Belin RM, Clickner R, Jeffries R, Phillips L \& Mahaffey KR. Serum TSH and total T4 in the United States population and their association with participant characteristics: national Health and Nutrition Examination Survey (NHANES 1999-2002). Thyroid: Official Journal of the American Thyroid Association 200717 1211-1223. (https:// doi.org/10.1089/thy.2006.0235)

5 Thompson PD, Clarkson P \& Karas RH. Statin-associated myopathy. Journal of the American Medical Association 2003289 1681-1690. (https://doi.org/10.1001/jama.289.13.1681)

6 Tokinaga K, Oeda T, Suzuki Y \& Matsushima Y. HMG-CoA Reductase Inhibitors (statins) might cause high elevations of creatine phosphokinase (CK) in patients with unnoticed hypothyroidism. Endocrine Journal 200653 401-405. (https://doi.org/10.1507/endocrj. k04-144)

7 Veenstra J, Smit WM, Krediet RT \& Arisz L. Relationship between elevated creatine phosphokinase and the clinical spectrum of rhabdomyolysis. Nephrology, Dialysis, Transplantation 1994 9 637-641. (https://doi.org/10.1093/ndt/9.6.637)

8 WHO. Adherence to Long-Term Therapies: Evidence for Action: World Health Organization 2003

9 Nieuwlaat R, Wilczynski N, Navarro T, Hobson N, Jeffery R, Keepanasseril A, Agoritsas T, Mistry N, Iorio A, Jack S, et al. Interventions for enhancing medication adherence. Cochrane Database of Systematic Reviews 201411 CD000011. (https://doi. org/10.1002/14651858.CD000011.pub4)

10 Walker JN, Shillo P, Ibbotson V, Vincent A, Karavitaki N, Weetman AP, Wass JA \& Allahabadia A. A thyroxine absorption test followed by weekly thyroxine administration: a method to assess non-adherence to treatment. European Journal of Endocrinology 2013168 913-917. (https://doi.org/10.1530/EJE-12-1035)

Revised version received 13 April 202

Accepted 13 May 2021 